No women in the 24-hour group, two women in the 48hour group and seven in the 72-hour group aborted prior to the misoprostol. Only three women in total required surgical evacuation. No women required blood transfusion and there were no admissions for overt pelvic inflammatory disease following the procedures. Women who started hormonal contraception immediately after the procedure did not experience more bleeding problems.

A small number of women did not present for follow up but all local antenatal and gynaecological care is carried out in our unit and it is most unlikely that major problems occurred of which we were unaware. The follow-up period extended for several months after completion of the study and no late complications were identified. The overall incidence of problems was very low.

\section{Discussion}

Our study supports the findings of Schaff et al. ${ }^{4}$ that a more flexible regimen of mifepristone/misoprostol administration is very effective for medical TOP. In the 72hour group, more women aborted following mifepristone alone and there was a tendency to require fewer subsequent doses of misoprostol.

At all gestations the administration of a second dose of misoprostol if abortion has not already occurred after 4 hours helps to ensure that termination occurs completely. This practice has recently been confirmed in a study by Ashok et al. ${ }^{6}$ In our study there was a low requirement for surgical evacuation for incomplete procedures and a very small number of continuing pregnancies. This makes these regimens appropriate for use in all women up to 84 days' gestational age.

Approximately $30 \%$ of women with pregnancies with a gestational age of 70-83 days required further doses of misoprostol to effect abortion. If the women are prepared for the possibility of a lengthier procedure, the subsequent complete abortion rate is also very good. Initially when our unit commenced performing the terminations at 70-83 days' gestation women were allowed home at 1600 hours even if abortion had not occurred. Two pregnancies (Table 2) remained viable at review and subsequent management was more difficult because of the increased gestational age. It was therefore decided to change the discharge policy in these later gestations to ensure that products of conception were identified prior to the woman going home. This does not seem necessary for gestations up to 69 days as most terminations complete at home even if not completed in hospital.

The failure rate in the 24-hour group appears higher than the other two groups but is still within acceptable limits. The two women with ongoing pregnancies in the $\leq 69$ days' gestation group received oral misoprostol. Our patients are encouraged to accept vaginal misoprostol due to its increased effectiveness but occasionally women still opt for oral administration. ${ }^{?}$

In conclusion, the numbers in this initial study are small but the results suggest that an increased flexibility in the timing of mifepristone and misoprostol administration contributes to the acceptability of the procedure without decreasing its efficiency. We have shown that flexible regimens can be used successfully in a local service catering for all women presenting for medical TOP up to 84 days' gestation.

\section{Statements on funding and competing interests}

Funding. None identified.

Competing interests. None identified.

References

1 UK Multicentre Study: final results. The efficacy and tolerance of mifepristone and prostaglandin in termination of pregnancy of less than 63 days' gestation. Contraception 1997; 55: 1-5.

2 Gouk EV, Lincoln K, Khair A, et al. Medical termination of pregnancy at 63 to 83 days' gestation. Br J Obstet Gynaecol 1999; 106: $535-553$.

3 Ashok PW, Templeton A. Nonsurgical mid-trimester termination of pregnancy: a review of 500 consecutive cases. Br J Obstet Gynaecol 1999; 106: 706-710.

4 Schaff EA, Fielding SL, Westhoff C, et al. Vaginal misoprostol administered 1,2 , or 3 days after mifepristone for early medical abortion: a randomized trial. JAMA 2000; 284: 1948-1953.

5 Creinin MD, Schwaretz HC, Pymar HC, et al. Efficacy of mifepristone followed on the same day by misoprostol for early termination of pregnancy: report of a randomized trial. $\mathrm{Br} \mathrm{J} \mathrm{Obstet}$ Gynaecol 2001; 108: 469-473.

6 Ashok PW, Templeton A, Wagaarachchi PT, et al. Factors affecting the outcome of early medical abortion: a review of 4132 consecutive cases. Br J Obstet Gynaecol 2002; 109: 1281-1289.

7 El Refaey H, Rajasekar D, Abdalla M, et al. Induction of abortion with mifepristone (RU486) and oral or vaginal misoprostol. $N$ Engl J Med 1995; 332: 983-987.

\author{
Abstract \\ Background. The need to improve the quality and \\ availability of information on sexual health is identified as \\ a key element in achieving the aims set out in the National \\ Strategy for Sexual Health and HIV. Providing information
}

\title{
Providing information for young people in sexual health clinics:
}

Roslyn Kane, RGN, MSc, Research Fellow, Sexual Health Programme; Wendy Macdowall, BSc, MSc, Research Fellow, Centre for Sexual Health Research; Kaye Wellings, MSc, FPPHM, Reader and Director, Centre for Reproductive and Sexual Health

Correspondence: $R$ Kane, Sexual Health Programme, Department of Public Health and Policy, London School of Hygiene and Tropical Medicine, Keppel Street, London WC1 7HT, UK. Tel: +44 (0) 207927 2177. E-mail: Roslyn.Kane@

(Accepted 12th February 2003)

Journal of Family Planning and Reproductive Health Care 2003; 29(3): 141-145

about sexual health to young people poses particular challenges because of the sensitive nature of the issues and because of the difficulties that young people may face in sourcing information and asking questions of professionals. 
Objective. To explore the views of young people attending sexual health services on several aspects of service delivery, including provision of information.

Method. Twenty-five in-depth qualitative interviews were conducted with a purposive sample of young people attending a range of different outlets for sexual health care. Results. This research revealed important information about the ways in which the type, format, tone and design of health promotion materials and the methods used to impart information to young people has a strong impact on client satisfaction during visits to sexual health services.

Conclusions. Young people vary greatly in their needs for sexual health information in terms of level, extent and manner of provision. Passive acceptance of information should not be taken to indicate tacit satisfaction with level and complexity. Written information needs to be used in conjunction with face-to-face discussion. Effective provision of sexual health information impacts notably on client satisfaction. Pitched at the right level, sexual health information has considerable potential to enhance sexual health status.

\section{Key message points}

- Young people vary greatly in their needs for sexual health information in terms of level, extent and manner of provision.

- Passive acceptance of information should not be taken to indicate tacit satisfaction with level and complexity.

- Written information needs to be used in conjunction with faceto-face discussion.

- Effective provision of sexual health information impacts notably on client satisfaction.

\section{Introduction}

The need to improve the quality and availability of information on sexual health is identified as a key element in achieving the aims set out in the National Strategy for Sexual Health and HIV. ${ }^{1}$ A recent study cited better information for young people, including materials specifically designed for teenagers, as one of the most important ways of improving local teenage sexual health services. ${ }^{2}$

The problem of deficiencies in both information provision and patient involvement in decision making is not exclusive to sexual health. ${ }^{3,4}$ Providing information about sexual health poses particular challenges, however, because of the sensitive nature of the issues and the difficulties faced by young people in sourcing information and asking questions of professionals. ${ }^{5}$ Young people want access to good information and to be able to discuss sexual matters openly. ${ }^{6}$ Yet research has shown them to be critical of the amount and quality of information about contraceptive methods received from providers. $^{7}$

There is agreement that young people need better information on the range of contraceptives available, $, 8,9$ more advice about the effectiveness and potential side effects of particular methods, and clear instructions about method use. Less is known on how information should be presented. In this paper we explore the experiences of young men and women receiving information during visits to young people's sexual health clinics; their likes and dislikes; what they wanted to know more about and in what format.

\section{Method}

This study developed from a larger research project that had the overall aim of developing a protocol for the evaluation of sexual health services for young people. ${ }^{10}$ As part of this study young people's views were collected on several aspects of sexual health service delivery, including provision of information. In-depth, semi-structured interviews were conducted face-to-face in a range of service settings using a topic guide designed to explore client views relating to the organisation and delivery of sexual health services.

Developing the topic guide

The topic guide was developed after review of the relevant literature. This identified the following components of service provision, crucial to good practice:

- Acceptability of service

- Accessibility of service

- Appropriateness of advertising strategy

- Appropriateness of service to all client groups

- Choice of services

- Degree of confidentiality

- Extent of follow-up/outreach activities

- Quality/quantity of information imparted at services.

A purposive sampling strategy was applied to ensure that clients were selected from a variety of different types of service setting. The services included have been broadly categorised as follows:

Service type A: service targeted at and dedicated to young people, providing both contraceptive care and full sexually transmitted infection (STI) diagnosis and treatment during the same session.

Service type $B$ : service located within a genitourinary medicine (GUM) clinic with special sessions held specifically for young people where contraceptive and full STI care are offered.

Service type $C$ : service held within a community family planning clinic, open to women of all ages though young people are encouraged to attend at specific times. Some STI diagnoses can be made but referral is necessary for treatment of infection.

Respondents were selected by means of a purposive sampling strategy in order to ensure that both young men and young women from a wide age range and from a variety of ethnic backgrounds were represented. The aim was to achieve a sample which was felt to be representative of the 'usual' clinic population. A total of 25 young people were interviewed.

Service users were approached as they waited to go in for their consultation, and were asked if they were interested in taking part in a study. An information sheet describing the purpose of the research and the importance of their views was provided and they were given the opportunity to discuss it, or ask further questions about the study.

Once they had agreed to be involved, they were asked to sign a consent form prior to the interviews and were given a small financial reward ( $£ 10$ gift vouchers).

Interviews were conducted within the clinic in private, and took place immediately after their consultation so that respondents could refer to their recent experience. Assurances were given that the interview would be confidential and that responses would not affect future treatment in any way. Interviews lasted for around 40 minutes and were tape-recorded and transcribed verbatim.

Three respondents requested that a friend or partner accompany them during the interview. One declined to have the interview tape recorded, and in this case extensive notes were taken by the interviewer and written up in full immediately afterwards. Transcripts were analysed using the Framework method of carrying out content analysis on qualitative data. ${ }^{11}$ Data from each interview were summarised in spreadsheet format, followed by interpretative analysis of the charted data in order to identify patterns, explanations and hypotheses. Two researchers coded the first few transcripts and discussed 
any disagreements in order to improve the reliability of coding.

\section{Results}

Level of information required

Twenty-five young people agreed to participate. The age and gender breakdown of the participants is shown in Table 1.

The level of information presented in consultations emerged as a critical consideration in client satisfaction. How much detail should be provided, however, was very much a matter of personal choice. For some, the information given, particularly in written form, was at too complex a level. The sheer volume of facts to be read before using contraception proved a deterrent to use. [NB. In the quotes that follow, $\mathrm{R}$ indicates the respondent and I the interviewer.]

$\mathrm{R}$ : “Like for the morning after pill, you've got this little booklet with tiny microscopic text (laughs) - it seems like pages and pages and all you want to do is take the blasted pill ... she knew I just wanted to take the pill and didn't want to read all that mumbo-jumbo so she gave me a nice little easy one (laughs)."

(Female, 21 years, Service type C)

One young woman claimed she had not started to use her oral contraception because she did not understand the accompanying information sheet.

R: "I just haven't took it because I don't understand it (friend laughs), but if you read it it's so confusing and then they've got all these charts...."

I: "So you've got the pill at home but the reason you haven't started it is because of all the small print?"

R: "Yeah."

(Female, 14 years, Service type C)

The preference in these cases was for simplified, concise information, focusing on essential details. Those who were interested, it was suggested, could find out more if required.

Other young people reported not having received enough information. One young woman, who had had an adverse experience of oral contraceptive use, reported having been told too little about alternatives. She was disappointed that information was not offered spontaneously and did not feel it was her responsibility to ask for it. Another felt that staff might be wary of spending too long giving information to those who may not be interested.

The issue of whether information should be passively received, or actively sought, was also raised in the interviews. The general view was that not asking should

Table 1 Age and gender breakdown of the study participants

\begin{tabular}{lll}
\hline Age (years) & Male (n) & Female (n) \\
\hline 13 & & 1 \\
14 & & 2 \\
15 & $1(+1$ partner) & 4 \\
16 & & 2 \\
17 & 1 & 1 \\
18 & & 3 \\
19 & & 1 \\
20 & & 2 \\
21 & $1(+1$ partner $)$ & $3(+1$ friend $)$ \\
22 & & 2 \\
23 & & 1 \\
\hline
\end{tabular}

not be interpreted as not wanting. This related not only to written information but also to that conveyed during a consultation. One young woman who had signs of a urinary tract infection expressed the feeling that she had come away ill-informed and confused about her diagnosis.

R: "I was hoping that they would have explained to me exactly. They told me what my symptoms were about but they didn't tell me exactly how it is caused or what is going to happen. I would have liked them to explain things more 'cos they didn't ask me if I was sexually active and that. I think they could have offered more." (Female, 16 years, Service type C)

Age did not appear to be related to willingness to receive or understand complicated information. Some of the youngest respondents (i.e. those aged 13 and 14 years) in this study expressed a need and desire for thorough information and practical instruction on the correct use of contraception.

We probed if time taken was a factor in whether detailed information is welcomed, in view of the fact that this might add to the length of the consultation. The consensus seemed to be that once the effort had been made to visit the clinic in the first place, the time spent there was of less concern than receiving thorough care.

Young people appreciated the time taken by staff to provide thorough information, particularly in relation to oral contraceptive use. Typically, the consultation with the doctor was followed by a session with a nurse who discussed things in more detail and adopted a more pastoral role.

\section{Format of information}

We enquired about preferences for the form in which information should be presented, and in particular whether it should be spoken or written. Responses were more or less equally divided between the two. Those in favour of the written word pointed to the ease with which leaflets could be used following the consultation, enabling issues to be considered which did not come up during the consultation. This seemed particularly important in instances in which young clients felt vulnerable and perhaps unable to absorb verbal information at the time of their visit.

$\mathrm{R}:$ "I think it was better that I was able to go away and read them rather than being told. I don't think I would have listened to everything she would have said, so in that respect it was good ...if I forget I can then read it." (Female, 17 years, Service type A)

Another advantage of leaflets was that they could be left lying around for clients to browse and select those of interest. Time is limited during the consultation and it was felt by some that written information can be taken away and examined at leisure.

I: "So did you also get leaflets about sexual health things, infections and contraception?"

R: "Yeah."

I: "How do you feel about having all that material?"

R: "Yeah, it's alright, I can read it all later and know what's happening."

I: "So do you think you will read it?"

R: “Yeah.” (Female, 14 years, Service type B) 
Those in favour of the spoken word held that leaflets were often dealt out by staff because "it's quicker" but were unlikely to be read by the young people in the clinics. A preference for personally delivered information was expressed on the grounds that this provides an opportunity to clarify anything during the process of the consultation itself and avoids a situation in which people find themselves back at home before they have had the chance to think of any questions. Others simply preferred to have someone talking to them.

R: "I don't like reading, I prefer someone telling me face-to-face and explaining it, "cos when you read through things it comes out all muddled and ..."

(Female, 15 years, Service type A)

$\mathrm{R}$ : “... if you get given a leaflet ... if you take it home you don't read it, it goes on a shelf, or you put it in the bin or whatever." (Female, 20 years, Service type A)

Other young people were of the view, however, that the two forms of delivery complemented one another, and that leaflets served to augment information provided during a consultation. Some felt that written material may be necessary only when information given verbally is insufficient or when the young person had little existing knowledge of the topic being discussed.

I: "Were you given any information leaflets by the doctor or the nurse?"

R: "No."

I: "So you were just given verbal information?"

R: "Yeah."

I: "How did you feel about that?"

$\mathrm{R}$ : "Erm, if I didn't know anything about it, then it wouldn't have been enough information but because ... She did actually ask me if I knew certain things and then the doctor asked me if I knew certain things so I was basically ..."

I: "Oh I see, so they kind of assessed your own knowledge first?"

R: "Yeah, and then they actually just ... Otherwise I would have needed some leaflets and some information to think about it."

I: "So you felt quite happy about it?"

R: "Yeah, for me, but probably for someone else that wouldn't have it done, they could have questioned them and they would have known a certain amount and they probably would have needed the leaflets to give them that much more knowledge."

(Female, 18 years, Service type B)

Again, the main challenge to health professionals appears to lie in striking the right balance. The above excerpt illustrates how the extent of existing knowledge may quickly be assessed and the amount of information imparted, adjusted accordingly. There was evidence that this was not always achieved.

$\mathrm{R}$ : “... mostly they don't really sort of talk you through the actual contraception here. What I've found is that they just give you a leaflet and you go away and read it and then if you've got any questions you come back"
I: "So, they didn't actually explain the leaflet to you when they gave it you?"

R: "Not as far as I can remember honestly. I mean she just gave me the leaflet..."

(Female, 23 years, Service type C)

Other formats, particularly posters, were also appreciated by those we spoke to, though they were considered less suitable for conveying sensitive information.

$\mathrm{R}$ : "I know it's not a crime looking at a poster but everyone's looking at that poster over there because it's not embarrassing and they aren't looking at that one over there."

I: "People might think, why is he reading about that?"

R: "Yeah, that's it, has he got that?"

I: "Is it the same for leaflets though, so you think that people are embarrassed by ...?"

R: "You can hold them, you can hide them ..."

(Male, 19 years, Service type A)

\section{Content of information}

Some participants welcomed quite a high level of technical and medical detail, in helping to ally anxieties and provide reassurance and confidence. Even statistical information, which might generally be considered less palatable, was welcomed by some. Indicating the burden of infection in the population as a whole seemed to be effective in putting individual problems into perspective.

R: "I'm not that embarrassed about the situation because the doctor explained the statistics, there's about 60000 that had genital warts last year, it's amazing, it puts you at ease a bit more, just to know that everyone else ..."

(Male, 19 years, Service type A)

There was support for information being offered on a wide range of issues relating to sexual health and not simply those connected with the primary reason for attending. Young people coming to the clinic for contraception, for example, appreciated also receiving information relating to STIs and drugs.

R: "They gave me some leaflets about the pill, and they also gave me leaflets about infections and viruses that you can get and that ... It was good, it was useful." (Female, 15 years, Service type A)

\section{Tone of information}

The importance of gauging an appropriate tone and style of information was evident, in particular the need to design material with the target group in mind.

I: "Do you think there is room for improvement there?"

R: "Big time. Big time, it's boring! The way it's laid out. I think it just could be a bit more punchy. It seems quite simple. It just doesn't ... there's a lot to read. Definitely."

(Female 19 years, Service type C)

Young people felt that the information materials needed to be written with their target audience in mind, using language appropriate to them. If terms are too 'medicalised' the meaning may be lost on the young reader.

The use of humour was recognised as being a beneficial 
way of getting information across and was appreciated for its potential to reduce embarrassment and draw attention to health promotion material, particularly among young male clients.

R: "I think they have got it right. The books and things are really amazing, I don't remember seeing anything like that before, and it's something you can take home and show people and everyone can have a laugh at it and learn something along the way. No one would feel embarrassed about reading it, because it's funny, because it's a comic."

(Female, 20 years, Service type A)

\section{The role of information in client satisfaction}

There was evidence in these interviews that the offer of free and readily available information provides an incentive to young people to attend services. This was noted particularly by those attending open-access clinics, using the facilities as a resource centre without a formal consultation with the medical staff. One respondent, who for months had avoided attending the clinic, was so impressed with the amount of information on offer, said that had he been aware of how accessible the information was then he would have attended sooner. For some, the amount and quality of information offered was held to be one of the best things about the service, and a factor in the decision to make a repeat visit.

I: "And what other things did you like, or would recommend, about this service?"

R: "Um ... I liked all the little books and leaflets that they've got lying around."

(Female, 20 years, Service type A)

$\mathrm{R}$ : "I remember the first time I came here they gave me loads of leaflets, I sat and talked to the consultant for ages ... that's why I came back, because they treated me so well." (Female, 16 years, Service type A)

\section{Discussion and conclusions}

Our data show considerable diversity in information needs and preferences among young people. While some young clients welcome detailed information, others prefer more concise explanations; some favour face-to-face discussion, others the written word; and while some have the capacity to understand quite detailed medical information, for others information pitched too high is unlikely to be retained.

Some of our findings concur with those of others, for example, that information leaflets are optimally used together with other forms of communication; ${ }^{12,13}$ and that a common complaint among young people is that health professionals frequently underestimate patients' desire for and ability to cope with information ${ }^{4}$ and assume too much existing knowledge about contraception. ${ }^{7}$

The diversity in individual information needs poses a challenge for health professionals. Striking the correct balance in the amount of information given to young people, correctly assessing individual information needs and tailoring the style, content and level of information to the client is a difficult task. A 'one size fits all' approach is unlikely to be effective. Provision of too little information risks leaving some clients feeling illinformed, whilst too much is likely to be counterproductive if service users feel overwhelmed, have difficulties of absorption or recall, or simply choose to ignore information being offered.
The evidence from these interviews is that young people in service settings may be quite passive and that health care professionals often receive few clues or cues from clients in this respect. Many young people may be reluctant to request additional information from a health professional and do not feel that the onus is on them to specifically request medical information since they may not always be aware of what there is to know.

Service providers may need to be more proactive in evaluating information provision in their own services to ensure that the right balance is achieved and maintained. Service users could be informed of the difficulties providers face in achieving the appropriate amount, format and level of complexity of information to young people. They could be consulted and invited to inform the clinic when they feel the information is inappropriate or inadequate and asked to suggest ways it might be improved.

These data suggest that the importance of effective provision of information may be greater than is generally imagined. Difficult though it may be to achieve, the provision of accurate, reliable and comprehensive information, pitched at the appropriate level, has considerable potential to enhance sexual health status.

\section{Acknowledgements}

The authors would like to thank staff at the sexual health services for allowing them access to their clients and allowing them to conduct the interviews in their premises. They are also grateful to all the young people who agreed to take part in this study.

\section{Statements on funding and competing interests}

Funding. This work was funded by the Mother and Child National R \& D Programme, NHS Executive, South East.

Competing interests. None identified.

References

1 Department of Health. The national strategy of sexual health and HIV. London: Department of Health, 2001.

2 Jolley S. Promoting teenage sexual health: an investigation into the knowledge, activities and perceptions of gynaecology nurses. $J A d v$ Nurs 2001; 36: 246-255.

3 Deyo RA. A key medical decision maker: the patient. BMJ 2001; 323: 466-467.

4 Coulter A, Entwistle V, Bilbert D. Sharing decisions with patients: is the information good enough? BMJ 1999; 318: 318-322.

5 Walker ZA, Townsend J. The role of general practice in promoting teenage health: a review of the literature. Fam Pract 1999; 16: $164-172$.

6 Evans T, Jacobs S. The Bodywise Initiative. J Child Health Care 1998; 2: 16-9.

7 Cooper P, Diamond I, High S. Choosing and using contraceptives. Integrating qualitative and quantitative methods in family planning. In: Preventing teenage pregnancy conference proceedings, IHPS Occasional Paper, Institute of Health Policy Studies (IHPS), University of Southampton, 1994.

8 Coleman J. Meeting the health needs of young people. J Epidemiol Commun Health 2001; 55: 532-533.

9 Family Planning Association (FPA). A model for district health authorities. Appendix A: Client needs: Checklist for purchasers; Appendix B: Services to be purchased for the DHAs clients. London: FPA, 1990.

10 Kane R, Wellings K. Evaluation kit: sexual health services for young people. London: London School of Hygiene \& Tropical Medicine, 2000.

11 Ritchie J, Spencer, L. Quantitative data analysis for applied policy research. In: Bryman A, Burgess R (eds), Analysing quantitative data. London: Routledge, 1994.

12 West J, Hudson F, Levitas R, et al. Young people and clinics: providing for sexual health in Avon. Report from the Department of Sociology, University of Bristol, Bristol, UK to Avon Health Authority 1995.

13 Phillips D, Pereira-Gray D, Owen M, et al. Family planning services in general practice and family planning clinics: a Devon case study. Institute of Population Studies and Postgraduate Medical School, University of Exeter, 1994. 